\title{
Process Simulation and Assessment of Crude Oil Stabilization Unit
}

\author{
Nejat Rahmanian $^{\mathrm{a}^{*}}$, Dhia Y. Aqar ${ }^{\mathrm{a}}$, Muhammad F. Bin Dainure ${ }^{\mathrm{c}}$, Iqbal M. Mujtaba ${ }^{\mathrm{a}}$ \\ ${ }^{a}$ Chemical Engineering Division, School of Engineering, University of Bradford, Bradford, BD7 1DP, UK \\ ${ }^{b}$ Chemical Engineering Department, Universiti Teknologi PETRONAS, Bandar Seri Iskandar, 31750 Tronoh, \\ Perak Darul Ridzuan \\ *Corresponding author: n.rahmanian@bradford.ac.uk
}

\begin{abstract}
Crude oil is an unrefined petroleum composed of wide range of hydrocarbon up to n-C40+. However, there are also a percentage of light hydrocarbon components present in the mixture. Therefore, to avoid their flashing for safe storage and transportation, the live crude needs to be stabilized beforehand. This paper aims to find the suitable operating conditions to stabilize an incoming live crude feed to maximum True Vapor Pressure (TVPs) of 12 psia (82.7 kPa) at Terengganu Crude Oil Terminal (TCOT), Malaysia. The simulation of the process has been conducted by using Aspen HYSYS.

The obtained results illustrate that the simulation data is in good agreement with the plant data and in particular for the heavier hydrocarbons. For the lighter components the simulation results over predict the plant data while for the heavier components this trend is reversed. It was found that at the outlet temperature $\left(85-90{ }^{\circ} \mathrm{C}\right)$ of hot oil to crude heat exchanger (HX$220 \mathrm{X})$, the high pressure separator (V-220 A/B) and the low pressure separator (V-230 A/B), had operating pressures of $(400-592 \mathrm{kPa})$ and $(165-186 \mathrm{kPa})$, respectively and the live crude was successfully stabilized to a TVP of less than 12 psia. The impact of main variables, i.e. inlet feed properties, three phase separators operating pressure and pre-heaters trains performance on the product TVP are also studied. Based on the scenarios analyzed, it can be concluded that the actual water volume $(\mathrm{kbbl} / \mathrm{d})$ has greater impact on the heat exchanger's duty, thus incoming free water to TCOT should be less than $19.5 \mathrm{kbbl} / \mathrm{d}(9.1 \mathrm{vol} \%)$ at the normal incoming crude oil flow rate of $195(\mathrm{kbbl} / \mathrm{d})$.
\end{abstract}

Keywords: Crude Oil Stabilization, TAPIS Blend, Crude Sweetening, True Vapor Pressure, Aspen HYSYS 


\section{Introduction}

\subsection{Background}

Crude oil is broadly categorized either as light or heavy. The characterization of crude oil can affect the stabilization way either thermally or using addition of chemical agents. The crude oil is characterized as the light oil if it is more volatile, whereas, it can be heavy oil if it is more viscous. The hydrocarbon components to be found in the oil reservoir range from the pure methane gas to the heavier hydrocarbons (mainly asphalt), which might cause fouling to the pre-heater's unit ${ }^{[1]}$. The main purpose of production facilities (oil and gas production terminal) are to separate the well stream into three components, typically called 'phases' (oil, gas and water), and process these phases into some marketable product(s) or dispose them in an environmentally acceptable manner. Separation is the main process, which is used to separate gas from liquid and water from oil. This is usually happened in a high-pressure vessel using the flashing of the hydrocarbon liquids ${ }^{[2]}$. The crude oil can be separated from the associated gases and the emulsion water by the flowing of well stream into the separator and the different specific gravity of hydrocarbons. Manning and Thompson ${ }^{[3]}$ stated that the dissolved gases in the crude oil must be completely removed to achieve the product considerations such as pipeline, storage, and tanker Reid Vapor Pressure (RVP) specifications. The presence of the most volatile hydrocarbons (such as methane, ethane, propane, etc.) in the crude oil can increase the value of RVP ${ }^{[4]}$. The removal of these dissolved hydrocarbon fluids can be made by using the crude oil stabilization operation. Crude oil stabilization is a pre-treatment operation, consisting of a number of flash drums and vapour-liquid separator vessels used to remove the light hydrocarbons along with hydrogen sulfide $\left(\mathrm{H}_{2} \mathrm{~S}\right)$ and to reduce the vapor pressure.

Hazard ${ }^{[5]}$ reported that the inlet crude undergoes to the further separation process as it can be separated the oil mixture into three phases (oil-gas-water) streams. Most terminals have different production separators, including a high-pressure separator (HP) to separate gas from the liquids. Then, liquids are further processed to a medium pressure (MP) separator to remove unseparated gas and the passes the liquids to a low pressure (LP) separator that removes even more gas and then separates water from the oil ${ }^{[6]}$. Vaezi et al. ${ }^{[7]}$ carried out a simulation and optimization study of $\mathrm{H}_{2} \mathrm{~S}$ expulsion from crude oil using the equilibrium model. Shankar et al. ${ }^{[8]}$ studied the steady state optimization and characterization of different types of crude oils using Aspen HYSYS. The four crude oil types were characterized in terms of the true boiling point (TBP) distillation curve, which are Arab light, Arab heavy, Bombay 
high, and Agbami crude oils. They found out that the Arab light crude produces more valuable light products than other crude oils. Rahmanian et al. ${ }^{[9,10]}$ have already studied the simulation and optimization of gas-condensate stabilization unit. They summarised different processes for the stabilisation of condensate. However, the crude stabilisation unit is different due to the less associated gas for the crude oil system. Tahouni et al. ${ }^{[11]}$ also studied effect of flow rate on condensate stabilisation unit in the same gas field as Rahmanian et al. ${ }^{[10]}$ and very limited studies found on the crude oil stabilisation unit. More recently, Edwin et al. ${ }^{[12]}$ performed the simulation and the optimization of crude oil stabilization scheme of Usan FPSO terminal. The net profit and optimal operating conditions such as feed flow rate, temperature and pressure against the Reid vapour pressure (RVP) of gasoline were studied. However, the effects of feed flow rate, temperature, and water flow rate, as well as the effect of low and high pressures of separator on the maximum true vapor pressure (TVP) of the product were not considered in their work, while, the impact of these operating variables are investigated in detail in this work. In this study, the process simulation and assessment using Aspen-HYSYS software can bring new insight in the quest for the good crude oil stabilization scheme. Furthermore, it would considerably improve the recovery amount of stabilized liquid, decrease $\mathrm{CO}_{2}$ emissions at the storage tanks and the annual production cost by reducing the process system constraint due to the pumping cavitation.

\subsection{Problem Statement}

Due to the decrease of pressure in the reservoir and consequent decrease of dissolved gas in the crude oil, the associated petroleum gas (off-gas) decreases also dramatically resulting to insufficient off-gas produced from the crude stabilization system in the crude oil receiving terminal, TCOT, Malaysia. This eventually leads to gas compressor surge and trip in the gas stabilization process. This can occur when the mass flow rate of gas to the compressor falls below a critical level with a higher-pressure drop across the machine. This 'surging' in the machine can be very harmful to the compressor, associated piping, and equipment due to high vibrations in the operating system. Furthermore, the management of oil-gas-water separation in petroleum and gas industries is very important and critical to achieve the standard storage/transport specifications while maintaining a marketable product quality. The crude oil constituent must be offered in an acceptable level to meet the customer requirements as tabulated in Table $1^{[13]}$. However, the free water content in crude oil to TCOT suddenly increases (water slug issues due to frequent pigging operation, twice a week) causing inefficient separation of liquid and gas, which can lead to low amount of off-gas production. 
The main objective of this study is to simulate the crude oil production unit in TCOT, which receives the inlet crude composition of Tapis Blend to obtain a desired crude product with TVP of $12 \mathrm{psia}(82.7 \mathrm{kPa})$ which is used for both storage and export. Then, the influences of operating variables i.e. inlet feed rate, three phase separators operating pressure and preheater's train on performance of crude oil stabilization operations are accessed.

\section{Methodology}

\subsection{Equation of State (EOS)}

For the selection of the most suitable thermodynamic package, the 'decision or selection tree' is used ${ }^{[14]}$. Figure 1 shows the selection tree of most suitable thermodynamic physical properties. The thermodynamic model is determined based on the physical characteristics of compounds that involved in the process. These characteristics are polarity, real or pseudo components, electrolyte, and the pressure. For oil, gas and petrochemical applications, the Peng-Robinson EOS ${ }^{[15]}$ is generally recommended the property package to be used since most of the components are non-polar or slightly polar and all real. Note also that, the same package was used by our previous works ${ }^{[9,10]}$. Real gases are comprised of specific components and unknown fractions with different molecular sizes and shapes, as well as phase interactions. As a matter of fact, the behaviour of real gases solely depends on molecular sizes and shapes and the specific phase interaction. Often corresponding state principles accurately account for the real gas molecules. Of course, some small corrections for binary interactions are provided by fitting to experimental vapour-liquid equilibrium (VLE) data. The deviation from ideality can be characterized by the compressibility factor $\mathrm{Z}$, where the real gases are modelled by taking into account their critical properties, acentric factors and binary interaction parameters using Peng-Robinson method.

Furthermore, the PR Fluid Package is most enhanced in HYSYS ${ }^{\circledR}$ and it covers the widest range of temperature and pressure and has special treatment for key components and largest binary interaction database. The staged separation (oil, gas and water separator) and preheater train are the main equipment, which provides the heat required to flash off the volatile components (C1-C5) and to break up oil - water emulsions in the crude oil.

Figure 2 shows the process flow diagram of the simulation of the crude stabilization system at TCOT. It can be seen from the flow diagram that the main equipment governing the crude stabilization process is the staged separation using three phase separators which are the highpressure separators (V-220 A/B), electrostatic precipitator (V-225 A/B) and low-pressure separator (V-230 A/B). The inlet crude from offshore platform (TAPIS Pump) at maximum 
temperature and pressure of $17 \mathrm{bar}$ and $27^{\circ} \mathrm{C}$, respectfully is firstly heated via crude to crude heat exchangers, HX-210 A-R and Hot Oil to crude heat exchangers, HX-220 A-D to achieve desired temperature for the staged separation process at $85^{\circ} \mathrm{C}$ before entering the first pressure vessel, V-220 A/B.

The crude oil is stabilized and dehydrated in a crude stabilization system prior to being stored in floating roof storage tanks. The produced off-gas from the crude stabilization unit, including the high pressure, and low-pressure separator, are collected and sent to gas stabilization header operation. It is transferred to liquefied petroleum gas recovery unit (LPGRU) and dew point control unit (DPCU), located in gas processing plant, GPP1 via gas compression system (Turbo Booster Compressor), and vapor recovery compressor, VRC-270 after hydration and condensation processes.

\subsection{The Effects of Operating Conditions}

In real plants, the operation unit is usually at unsteady state mode since there are several fluctuations in the operating parameters due to changing in surrounding conditions, upset in other related process unit upstream and breakdown of related equipment. As a result of these changes in input data, the specifications of the product can be also changed. However, it is very important to investigate the influence of these parameters that the process can tolerate and not to produce an off-specification product. To obtain those data, a one-dimensional study is carried out on the simulated crude stabilization system by manipulating several parameters, which listed below:

1. Inlet Feed Parameters
a. Dry feed volumetric flow rate
b. Free water flow rate
c. Inlet Temperature
d. Inlet pressure

2. Three Phase Separator Parameters
a. V-220 operating pressure
b. IV-225 operating pressure
c. V-230 operating pressure

3. Pre-Heater Train Performance
a. Heat exchanger duty (HX-210s \& HX-220X)
b. Fuel gas inlet flow rate
c. Furnace efficiencies (HX-610s)
d. Furnace duty

The product specification constraints are the product TVP (psia) and off-gas production (MMSCFD). Therefore, the TVP of the product is the most important specification that needs 
to be monitored carefully during the operation of the crude stabilization plant. The standard method for measuring TVP is ASTM 2879. Generally, there are two different methods to simulate crude oil stabilization system using HYSYS simulations are:

\subsubsection{Pseudo Component}

Hypothetical components which represents heavy component of crude oil in the process simulations which are created based on the laboratories characterization and crude sampling.

\subsubsection{Crude Assay}

The petroleum characterization method in Aspen HYSYS V10 converts all feedstock (crude oils, petroleum cuts and etc.) into a series of discrete hypothetical components based on their boiling point. Moreover, HYSYS pseudo components are obtained from the simulation and compared to the experimental results. On the other hand, HYSYS crude assay determined the properties of heavy components based on normal boiling points of each component.

\section{Results and Discussions}

\subsection{The Process Feed}

In analysing the performance of the TCOT process, the simulation study was performed using Aspen HYSYS V10. It is important to have more reliable operation model in describing the TCOT system because some of the data are not available from the plant and are only available via calculations from the HYSYS software. The feed stream and its composition are shown in Table 2. The bubble points and dew points curve of the inlet crude at different pressures and temperatures in the phase envelope diagram is displayed in Figure $3^{[16,17]}$. The physical properties (temperature and pressure) of feed from Tapis Pump (offshore platform) to TCOT are $27{ }^{\circ} \mathrm{C}$ and 17 bar (1801 $\mathrm{kPa}$ abs.). The phase envelope was calculated using Aspen HYSYS on the dry basis. The hydrocarbon feed is established in two equilibrium phases (vapour-liquid) between the bubble point and dew point curves as can be noted in ${ }^{[7]}$.

It can be noticed from Figure 3 that the liquid hydrocarbon phase fraction is 0.33 and aqueous phase fraction is 0.67 on the mole basis. This indicates that the feed is in three-phase region and thus, it can be processed in the Crude Stabilization Unit. As can be seen, based on the phase envelope above, the incoming feed is in pure liquid state. The incoming fresh crude oil from offshore platform usually comprises of produced water and also contaminant or typically referred as Basis Sediments \& Water (BS\&W). 


\subsection{Model Validation}

In order to ensure the validity of the simulation results, the mole fractions of the final product from Aspen HYSYS are compared with the plant data obtained from the crude stabilization unit in TCOT, Malaysia. Note, the process validation only was made in terms of the mole fraction of hydrocarbons against the list of process components in our earlier works ${ }^{[9,10]}$. The separation of crude oil is depended on the composition of the hydrocarbon fluids, their pressure, and temperature. The pressure of the fluids is controlled by the back- pressure regulator, whereas, the temperature can be regulated by expanding the fluid through a choke, addition of heat in a furnace or heating or cooling in a heat exchanger.

Note, it was found that the model validation in terms of the mole fractions of hydrocarbons against the real plant data is more powerful and reasonable in this study. Therefore, the separators should be designed carefully to handle fluids according to the fluid composition. The composition for 26 compounds of the product is presented in Figure 4. The trend of simulation results fits the real plant data fairly well. However, the compositions of the hydrocarbons lighter $\left(n-C_{1}-n-C_{6}\right)$ obtained from HYSYS software are slightly higher than those of the plant data. While, the compositions of the heavier hydrocarbons $\left(n-C_{22}-n-C_{36} *\right)$ match the real data well. This is because the undesirable hydrocarbons are flashed off during the crude oil stabilization by staged separation, which consists of three oil, gas and water separator vessel. Furthermore, the simulation product quality is generally similar to the actual data due to small variation about $3 \%$ and has no influence on the product purity considerations.

Figure 5 illustrates the mole fractions of the stabilized crude obtained by HYSYS simulations (Pseudo and Crude Assay) and the plant data. The main purpose of total validation is to identify the major differences between both simulations and compare them with the real data. It can be obviously seen from Figure 5 that both HYSYS $^{\circledR}$ simulation results predictions follow the trend of the plant data.

This excellent agreement was expected because of using the same Peng-Robinson EOS method for the both simulations. It can also be that for the both simulation, the mole fraction of components from methane to i-pentane are slightly higher than the plant data. Moving on to the heavy components, i.e. from n-pentane to carbon dioxide, Pseudo and Crude Assay results are better fitted the plant data as shown in Figure 5. Note also, the stabilized crude data generated by the simulation software are comparable to the plant data shows the validity of the simulation. Stabilized crude composition contains about $90 \%$ of heavy hydrocarbon and less amount of light hydrocarbon which is a positive factor for the crude storage. Volatile 
components such as methane and ethane were flashed off during stabilization process leaving only heavy hydrocarbon with lower vapor pressure. Normally, stabilized crude has true vapour pressure (TVP) of $12 \mathrm{psia}(82.7 \mathrm{kPa})$ at $37.8{ }^{\circ} \mathrm{C}$ and stored in floating roof tank in atmospheric conditions.

\subsection{Effects of Operating Conditions on True Vapor Pressure (TVP)}

\subsubsection{Effect of Feed Flow Rate}

The flow rate of normal feed employed for the base case study is $195(\mathrm{kbbl} / \mathrm{d})$. To study the influence of feed flow rate on the performance of the plant, the feed flow rate is initially reduced to $50 \%$ and then increased to $230 \%$ in $10 \%$ intervals. The impact of feed flow rate change on the TVP of the stabilized crude is depicted in Figure 6. As can be seen for both HYSYS simulation methods, increase in feed flow rate increases gradually the TVP of the product. This is explained by the knowledge that for the highest feed rate which requires to be stabilized, more heat amounts are needed to flash off the lighter hydrocarbons in the dead crude oil. Although the reboiler heat duty was kept constant, there is not enough energy to keep a constant TVP. It is noted from the graph that for an acceptable range of TVP from 1012 (psia), the highest flow rate percentage can be further processed by the crude stabilization plant (TCOT) at range of feed rate 139-205 (kbbl/d) respectively, unless the energy requirements are altered proportionately to the increasing flow rate by an appropriate feed ratio controller.

\subsubsection{Effect of Feed Temperature}

The inlet feed to the crude stabilization plant is normally at $27{ }^{0} \mathrm{C}$ from the offshore platforms. The feed temperature has been varied from $2{ }^{\circ} \mathrm{C}$ to $40{ }^{\circ} \mathrm{C}$ at $4{ }^{\circ} \mathrm{C}$ intervals in order to investigate the effects of feed temperature on the product TVP. Figure 7 presents the influence of feed temperature on the TVP of the stabilized crude. As can be seen from Figure 7 , the increase in the feed temperature can lead to huge reduction in the product TVP. The increase in the feed temperature would cause more portions of the light component to flash off easily from the crude and thus reduce the TVP of the product.

The crude stabilization plant can be tolerated in order to achieve the specified TVP (10 -12 psia) for a different range of the minimum environmental temperature (26 to $\left.38{ }^{\circ} \mathrm{C}\right)$. It is shown that any temperature lower than $26{ }^{\circ} \mathrm{C}$ would cause the stabilized crude become offspecifications as it will require a larger duty for the heat exchanger to heat the crude before entering the pressure vessels. 


\subsubsection{Effect of Free Water Flow Rate}

According to the TCOT design basis criteria, the surviving facility is capable of processing 21,600 barrels per day of free water content in the inlet crude in which equivalent to $4.8 \mathrm{vol} \%$ for 450,000 barrels of crude oil production per day. However, the average crude oil production is about 195 (bbl/d) based on the site information from year $(2011-2012)$. Thus the free water content is assumed $10 \%$ of the dry feed which is about 19.5 (bbl/d) $(9.09 \mathrm{vol} \%$ $\mathrm{BS} \& \mathrm{~W})$. The water flow rate is decreased to $2(\mathrm{bbl} / \mathrm{d})$ and then increased to a maximum of 29 (bbl/d) to examine the effects of water inlet flow rate on the crude stabilization operation, which is shown in Figure 8.

It can be seen from Figure 8 for both methods that as the water content inside the crude oil increases, the stabilized crude will also have higher TVP. As a result, the increase of water content will increase total mixture density and mass flow, which require a high duty of heaters/ heat exchangers to heat the process fluid to a suitable temperature before entering the pressure vessel. If optimum operating temperature cannot be achieved, it would affect the separation inside the pressure vessel thus results in less volatile component being flashed off to the stabilization gas header. The crude stabilization operation can tolerate to achieve the specified TVP is $20(\mathrm{bbl} / \mathrm{d})$ for a dry feed flow rate of $195(\mathrm{bbl} / \mathrm{d})$ for the maximum water content which is estimated around 10 vo1\% BS\&W. Any value higher than the recommended figure can be resulted in off-specification crude (TVP higher than 12 psia).

\subsubsection{Effect of High Pressure Separator, V-220 A/B Operating Pressure}

High Pressure Separator (V-220 A/B) is the first three phase separator in the crude oil stabilization system which normally operated at 67.59 psia $(465.6 \mathrm{kPa})$ of the operating pressure, and at $75-85^{\circ} \mathrm{C}$ of the temperature condition. The light compounds flashed off from the high-pressure separator are sent to the gas stabilization header prior for condensation and purification process. In order to satisfy the product specification requirements, the operating pressure of V-220 A/B is cut down to $330 \mathrm{kPa}$ and increased to $703 \mathrm{kPa}$. Figure 9 discusses the influence of low pressure separator pressure on the product TVP. As shown in Figure 9, as the operating pressure of $\mathrm{V}-220 \mathrm{~A} / \mathrm{B}$ increases, the stabilized crude product TVP progressively increases.

The increase in TVP of the product is a result of the increment in V-220 A/B operating pressure which means it lowers differential pressure between the incoming crude inlet and the pressure vessel. This results in small amounts of volatile components being flashed off at the high-pressure separator. Thus, there are still traces amount of volatile component in the 
rundown crude to storage which contributed to increase of product TVP. In order to ensure smooth operation without any upset to the operation, the high-pressure separator, V-220 A/B operating pressure should be kept around 65.27 - 72.52 psia. (449.9 -499.9 kPa)

\subsubsection{Effect of Low Pressure Separator, V-230 A/B Operating Pressure}

The operating pressure of low pressure separator $(\mathrm{V}-230 \mathrm{~A} / \mathrm{B})$ to the crude stabilization unit is set at $25.96 \mathrm{psia}(178.9 \mathrm{kPa})$ under normal temperature conditions between $75-85{ }^{\circ} \mathrm{C}$. Low Pressure Separator (V-230 A/B) is the last three phase separator in the plant. The light components flashed off from the low-pressure separator are sent to the gas stabilization header for further condensation and purification. To investigate the effects of low pressure separator $(\mathrm{V}-230 \mathrm{~A} / \mathrm{B})$ on the product TVP, the operating pressure is reduced to $14.94 \mathrm{psia}$ $(103 \mathrm{kPa})$ and then increased to $38.87 \mathrm{psia}(268 \mathrm{kPa})$ at 0.73 psia intervals.

The impact of low pressure separator pressure on the product TVP is presented in Figure 10. It can be noticed from Figure 10 that the increase in the operating pressure of $\mathrm{V}-230 \mathrm{~A} / \mathrm{B}$ for both simulation methods can lead also to increase the TVP value of stabilized crude product due to low pressure drop between the incoming crude inlet and the pressure vessel. As a result, very limited amounts of volatile compounds can be flashed off as gas phase at the high-pressure separator.

However, there are still traces amount of volatile component in the rundown crude to storage which contributed to increase of product TVP. In order to ensure smooth operation of the plant, the low-pressure separator, V-230 A/B operating pressure is being kept around 24.66 33.36 psia $(170-230 \mathrm{kPa})$.

\subsubsection{Effect of Hot Oil to Crude Heat Exchanger, HX-220X Outlet Temperature}

The normal outlet temperature of HX-210s to HX-220X used for the base case study is $85{ }^{\circ} \mathrm{C}$. The outlet temperature of HX-210s to HX-220X is kept constant at $52{ }^{\circ} \mathrm{C}$. In order to study the effect of changing HX-220s outlet temperature, the outlet temperature of HX-220s is reduced to $57{ }^{\circ} \mathrm{C}$ and increased to $97{ }^{\circ} \mathrm{C}$ instead of normal operation at $85{ }^{\circ} \mathrm{C}$ (no pigging activities).

Figure 11 shows the effect of HX-220s outlet temperature for both Pseudo component and crude assays) on the product true vapor pressure. As expected, the TVP is decreased as the outlet temperature of HX-210s increased (Figure 11). This means that as predicted the higher outlet temperature can remove more acid gases and lighter components and thus results in a lower TVP value. 
Meanwhile, more heat supply is needed to flash off the light (volatile) components inside the live crude coming from the offshore at the higher outlet temperature. Thus, it leaves only heavy and viscous components in rundown crude to storage with low vapor pressure. In summary, the impact of changing the outlet of HX-220s is very significant towards the crude oil stabilization operation.

Thus, in order to ensure smooth operation for the pre-heaters train, the outlet temperature of HX-220s should be kept around $85-90{ }^{\circ} \mathrm{C}$ with HX-210s outlet temperature is constant at 52 ${ }^{\circ} \mathrm{C}$. The effect of hot oil and furnace performance will be further discussed in the next section to analyze the limitation of the pre-heaters train.

\subsubsection{Fired Heater (HX-660) Analysis}

TCOT was designed with four fired heaters (HX-610 A/B/C/D) to heat up the hot oil (PETRONAS Danol XHT 32) from 150 to $260{ }^{\circ} \mathrm{C}$ with design efficiency of $89 \%$ for each fired heater. Under the full production load, $445 \mathrm{kbpd}$ of crude oil, the fired heaters are operated based on N+2 (100\% sparing philosophy) in which 12 burners (each fired heater with 6 burners) will be online. Fired heater, HX-610s was designed with the sole purpose to heat up the hot oil which will be sent to hot oil/crude heat exchanger, HHX-220X as a heating medium to heat up the live crude (inlet feed) to the optimum temperature $\left(85^{\circ} \mathrm{C}\right)$ in order to break the oil-water emulsion inside the live crude.

Currently, three fired heaters (12 burners online) are in operation with production load of 195 kbpd of crude. The major differences between the current operation and design specifications are given in Table 3. It is observed from Table 3 that the efficiency of the furnace system (HX-610s) has dropped below the design specification.

The calculated thermal efficiencies are a combined value for HX-610B C and D since only total fuel gas flow is available. Average calculated efficiencies during year 2010 were $38.38 \%$ which is $56.88 \%$ deviation from the design efficiency ( $89 \%)$. This indicates the fired heater performance cannot achieve $89 \%$ of efficiency even all the burners are kept online. Further maintenance and regular monitoring are important to increase the efficiency of the pre-heater train's performance.

In addition, several scenarios were analyzed to study which parameters give significant impact on pre-heaters train's performance. From all the analysis, it can be concluded that the actual water volume $(\mathrm{kbbl} / \mathrm{d})$ has a significant impact on the duty of HX-220X as compared to the water volume ratio. Since the design water volume is about $21.6 \mathrm{kbbl} / \mathrm{d}$ (which is equivalent to $4.8 \%$ of $450 \mathrm{kbbl} / \mathrm{d}$ ) at the average current plant production of $195 \mathrm{kbbl} / \mathrm{d} \mathrm{HX}$ - 
$220 \mathrm{X}$ is capable to handle water content up to $9.9 \mathrm{vol} \%$. During pigging operation, the water content was observed to receive an average of $15 \mathrm{vol} \%$, thus the pre-heater's capability to supply the heat required to flash off the volatile components is limited.

\section{Conclusions}

Process simulation and assessment of TCOT plant is conducted using Aspen HYSYS to study the effect of the operating conditions which may cause production of off-specification product. The aim of the study was to analyse and understand the mal-operation and shut down of the off-gas compressor in the plant which caused disruption of the plant and downstream units. TVP has been set as the criteria for the off-specification conditions of the product - that is, a highest of 12 psia if the incoming dry feed flow rate is kept fixed between $158-205 \mathrm{kbbl} / \mathrm{d}$ at pressure and temperature of 17 bar and $\left(24-32{ }^{\circ} \mathrm{C}\right)$, respectively.

The obtained results have been compared with the plant data to validate the process simulation. It is indicated form the comparison between the simulation and plant data that the process model is valid and very closely follows the trend of the actual data which can be used as a powerful tool for predicating of the plant under operation. The effect of operating conditions such as feed flow rate, feed temperature, free water flow rate, high pressure separator, low pressure separator, and temperature of hot oil to crude heat exchanger on the quality of product in terms of TVP and have been investigated.

It has been found that the operating pressure in high pressure separator (V-220 A/B) should be around (400 - $592 \mathrm{kPa})$, whereas, the low-pressure separator (V-230 A/B) pressure should be set around (165 - $186 \mathrm{kPa})$. Also, it has been found that to meet the TVP requirement, the outlet temperature of hot oil to the crude heat exchanger, HX-220X should be around $85-90$ ${ }^{0} \mathrm{C}$ with three fired heaters (HX-610 B/C/D) in the operation system.

\section{Acknowledgment}

The authors acknowledge PETRONAS Carigali Sdn. Bhd. Peninsular Malaysia Operation (PMO/PCSB) in Kerteh for their advice, support and guidance. 


\section{References}

[1] Sinnathambi CM, Nor NM, Ahmad MZ. Fouling characteristic and tendencies of Malaysian crude oils processing. Applied Sci. 2011 Oct;11:1815-20.

[2] Manish V.S. Practical Selection and Design Guide: For Gas Liquid Separators with Optimization. 2000.

[3] Manning FS, Thompson RE. Oilfield processing of petroleum: Crude oil. Pennwell books; 1995.

[4] Arnold JM, Stewart WC. Common property resource management in India. Oxford Forestry Institute, University of Oxford; 1991.

[5] Hazard Devold. Oil and Gas Production Handbook, ED 1.3, ABB ATPA Oil and Gas; 2006.

[6] Felder RM, Rousseau RW. Elementary principles of chemical processes, 1986.

[7] Vaezi, R., Atashi, H. and Tabrizi, F.F., Simulation and Optimization of $\mathrm{H}_{2} \mathrm{~S}$ Expulsion from Crude Oil with the Use of Equilibrium Model. International Conference on Chemistry and Chemical Process, Issue 10, 101-106, 2011.

[8] Shankar N, Sivasubramanian V, Arunachalam K. Steady state optimization and characterization of crude oil using Aspen HYSYS. Petroleum Science and Technology. 2016 Jul 2;34(13):1187-94.

[9] Rahmanian N, Ilias IB, Nasrifar K. Process simulation and assessment of a back-up condensate stabilization unit. Journal of Natural Gas Science and Engineering. 2015 Sep 30;26:730-6.

[10] Rahmanian N, Jusoh LS, Homayoonfard M, Nasrifar K, Moshfeghian M. Simulation and optimization of a condensate stabilisation process. Journal of Natural Gas Science and Engineering. 2016 May 31;32:453-64.

[11] Tahouni N, Khoshchehreh R, Panjeshahi MH. Debottlenecking of condensate stabilization unit in a gas refinery. Energy. 2014 Dec 1;77:742-51.

[12] Edwin M, Abdulsalam S, Muhammad IM. Process Simulation and Optimization of Crude Oil Stabilization Scheme Using Aspen-HYSYS Software. International Journal of Recent Trends in Engineering \& Research. 2017 May; 3(05).

[13] PETRONAS Carigali Sdn. Bhd. Stabilized Crude General Specifications (GS), 2008.

[14] Elliott JR, Lira CT. Introductory chemical engineering thermodynamics. Upper Saddle River, NJ: Prentice Hall PTR; 1999 Apr.

[15] Peng DY, Robinson DB. A new two-constant equation of state. Industrial \& Engineering Chemistry Fundamentals. 1976 Feb; 15(1):59-64.

[16] Tabrizi FF, Nasrifar K. Application of predictive equations of state in calculating natural gas phase envelopes and critical points. Journal of Natural Gas Science and Engineering. 2010 Mar 31;2(1):21-8.

[17] Shi J, Huang L, Li X, Sepehrnoori K. Production forecasting of gas condensate well considering fluid phase behavior in the reservoir and wellbore. Journal of Natural Gas Science and Engineering. 2015 May 31;24:279-90. 
APPENDIX: 


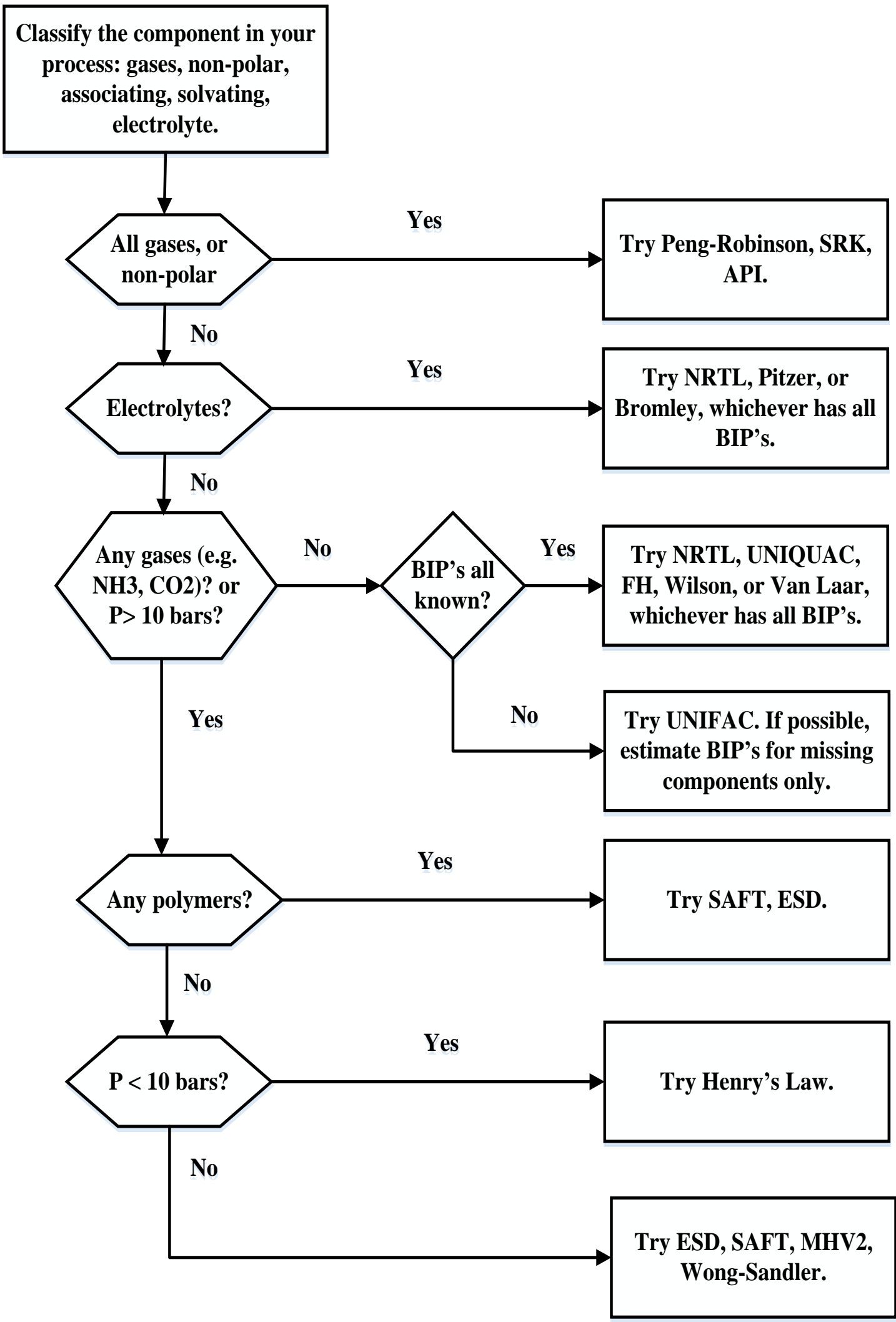

Figure 1 : Selection tree for selecting appropriate thermodynamic model (Elliot \& Lira, 1999). 


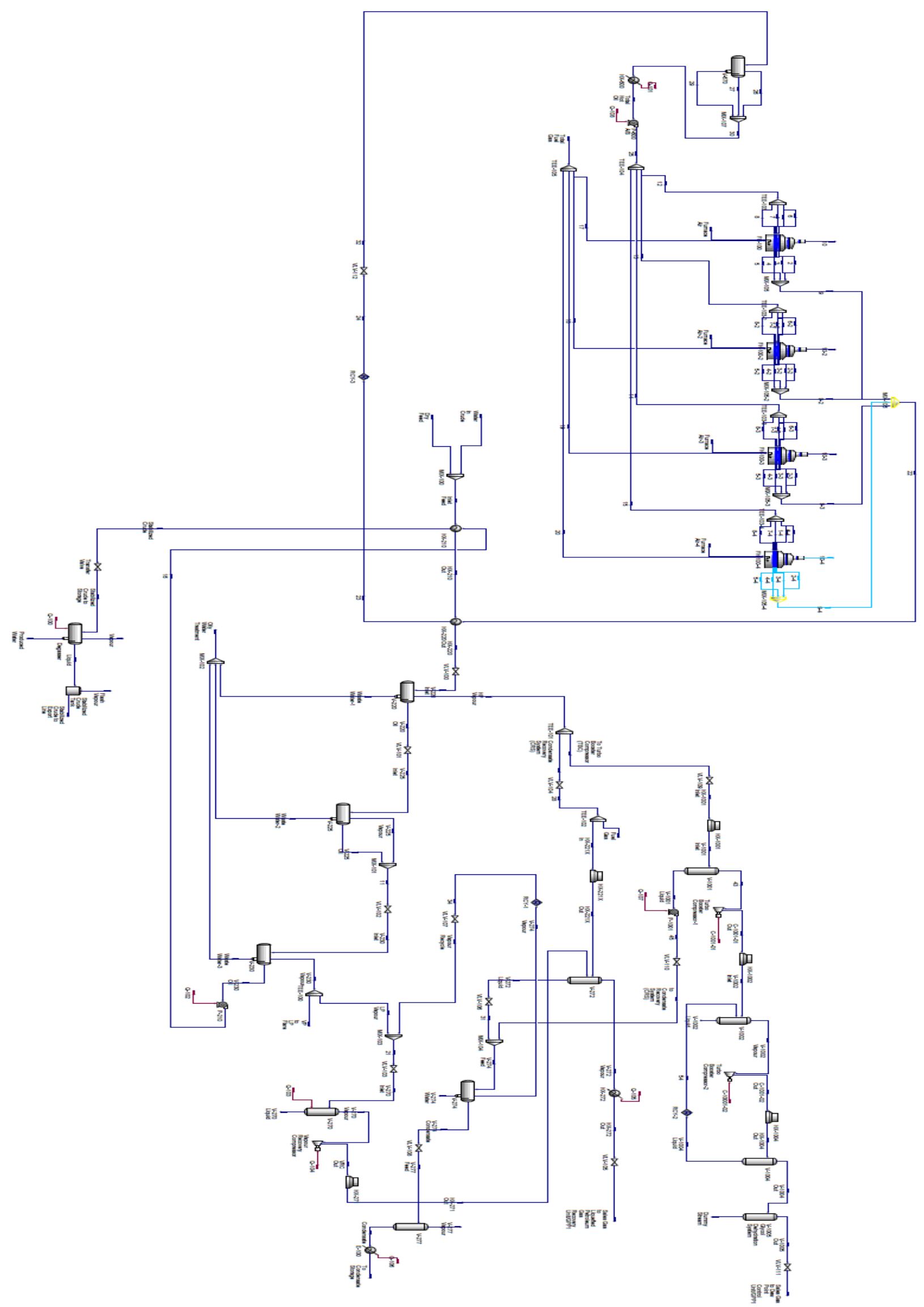

Figure 2: Process flow diagram for the crude oil stabilization system at Terengganu crude oil terminal (TCOT) using HYSYS Simulation. 


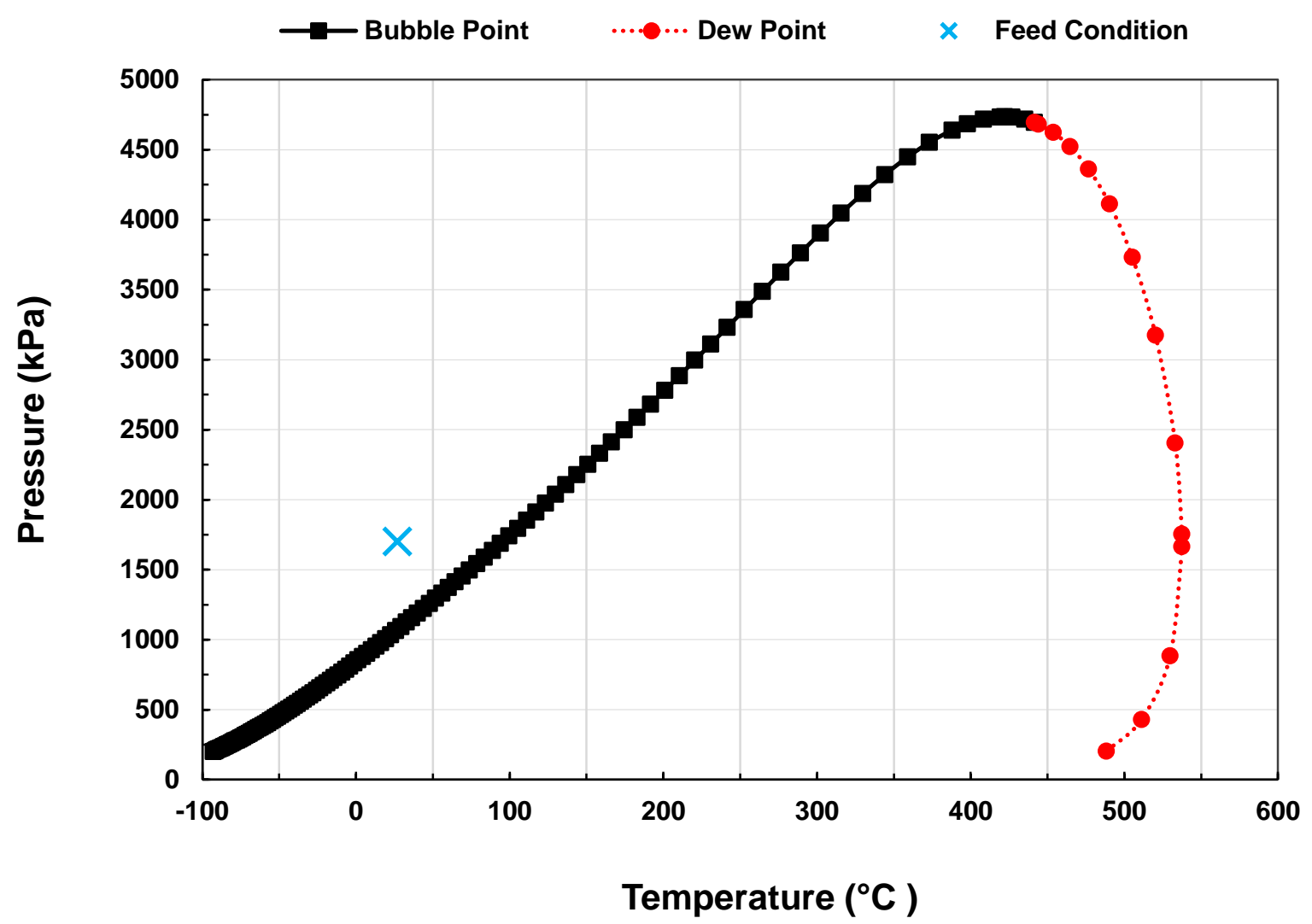

Figure 3: Phase Envelope Curve for the Inlet Feed.

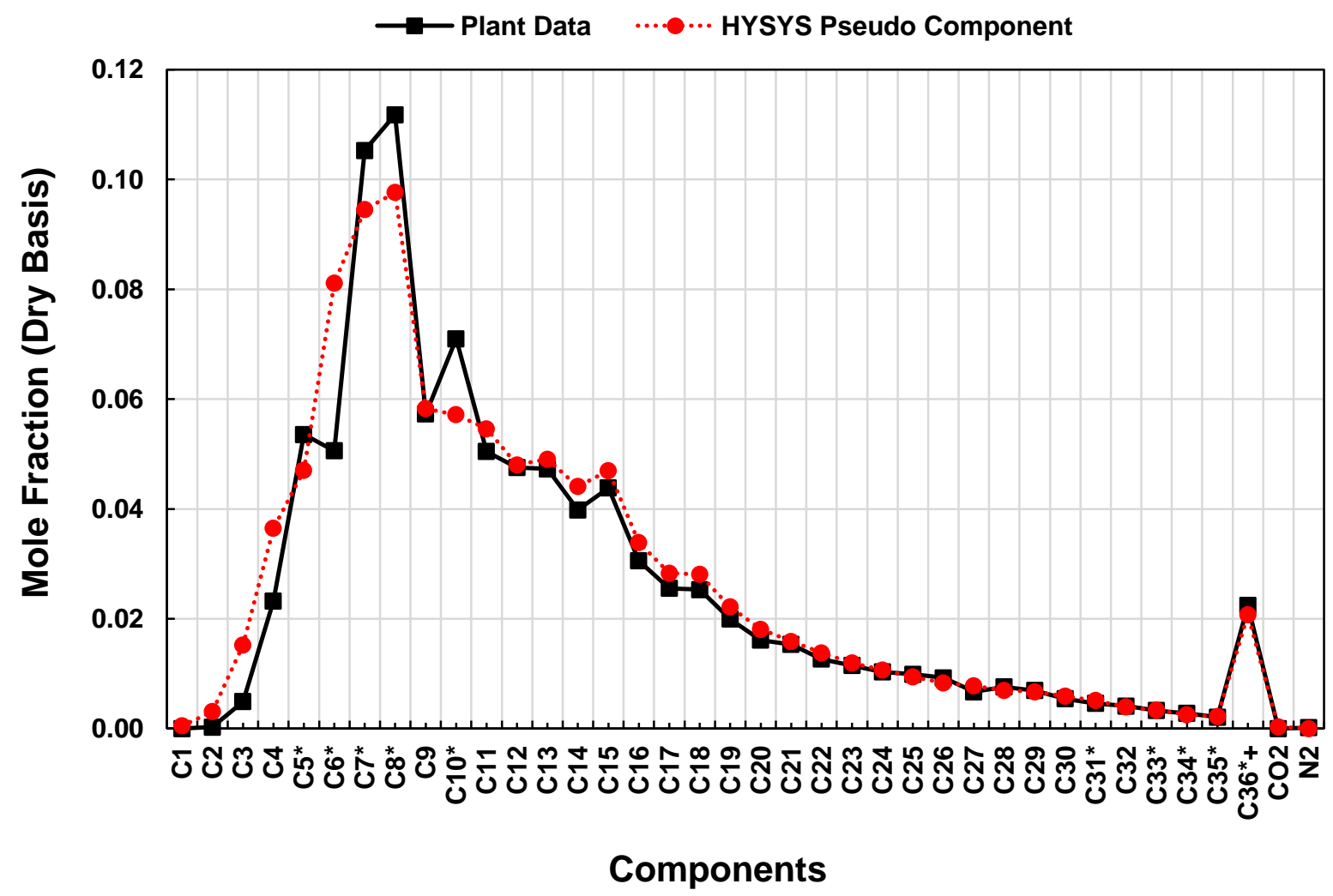

Figure 4: HYSYS Pseudo Component vs. Plant Data. 


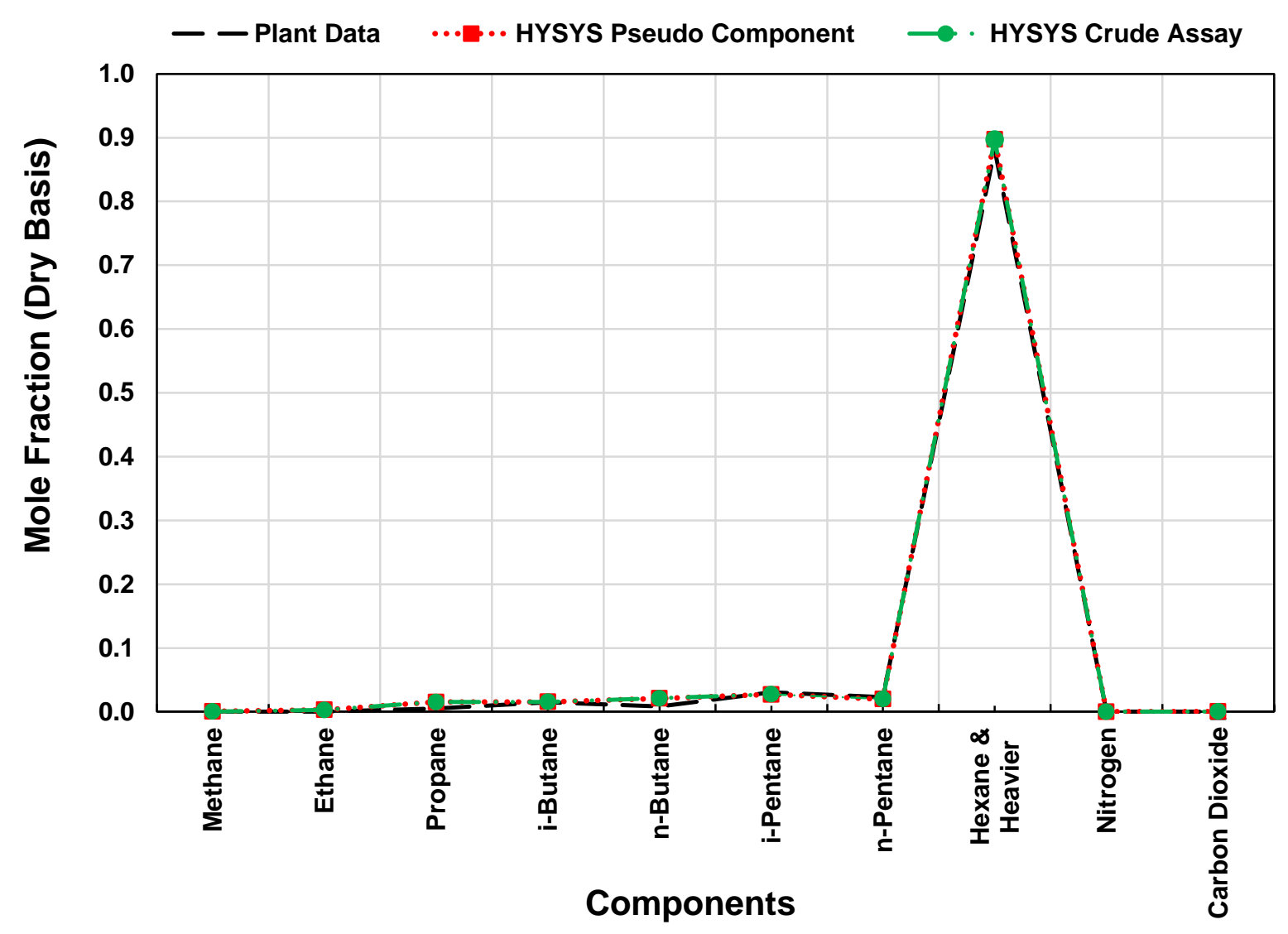

Figure 5: Total validation of HYSYS Software (Pseudo Component \& Crude Assay) vs. Plant Data.

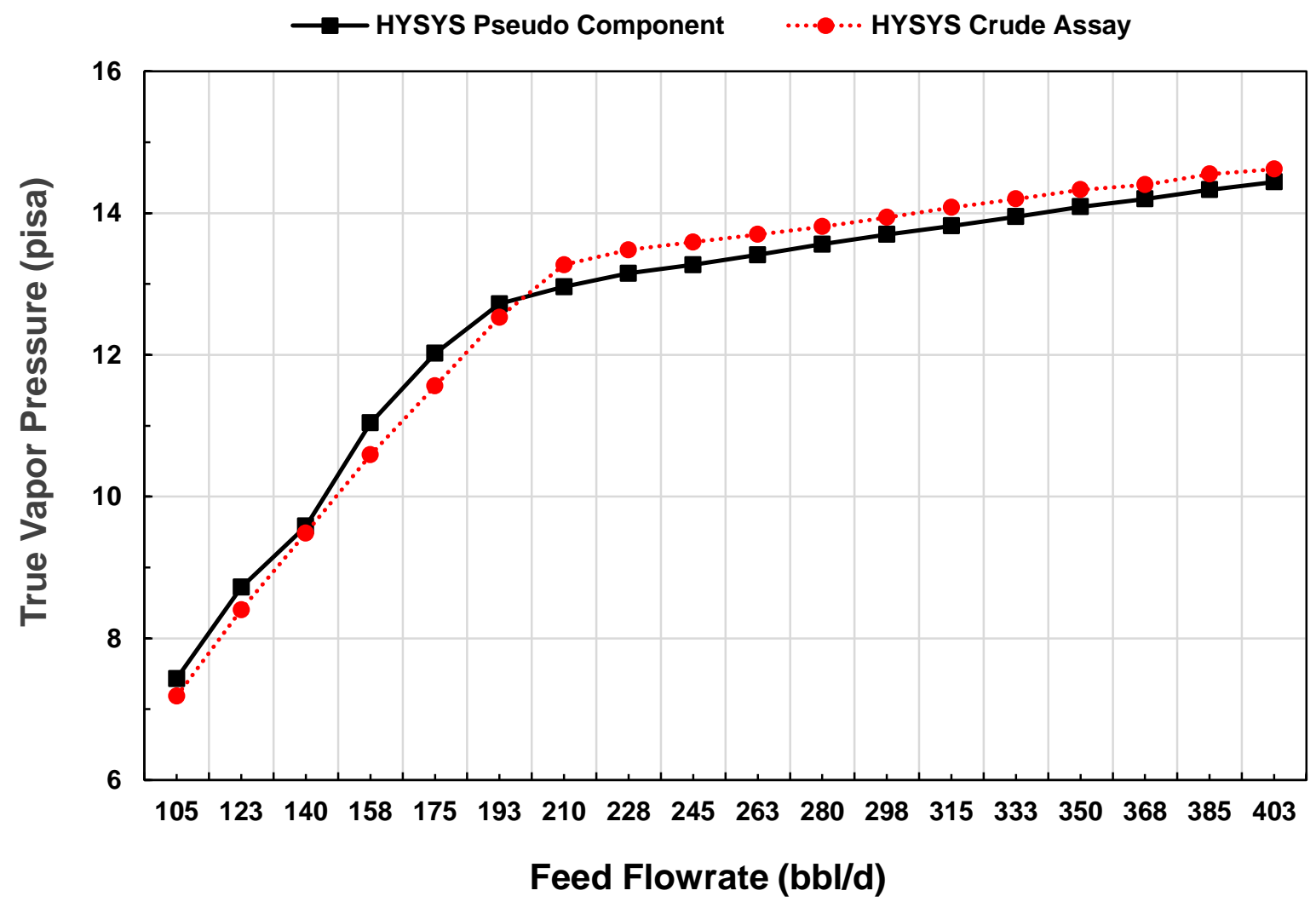

Figure 6: Effect of Feed Flow Rate on the TVP of the product. 


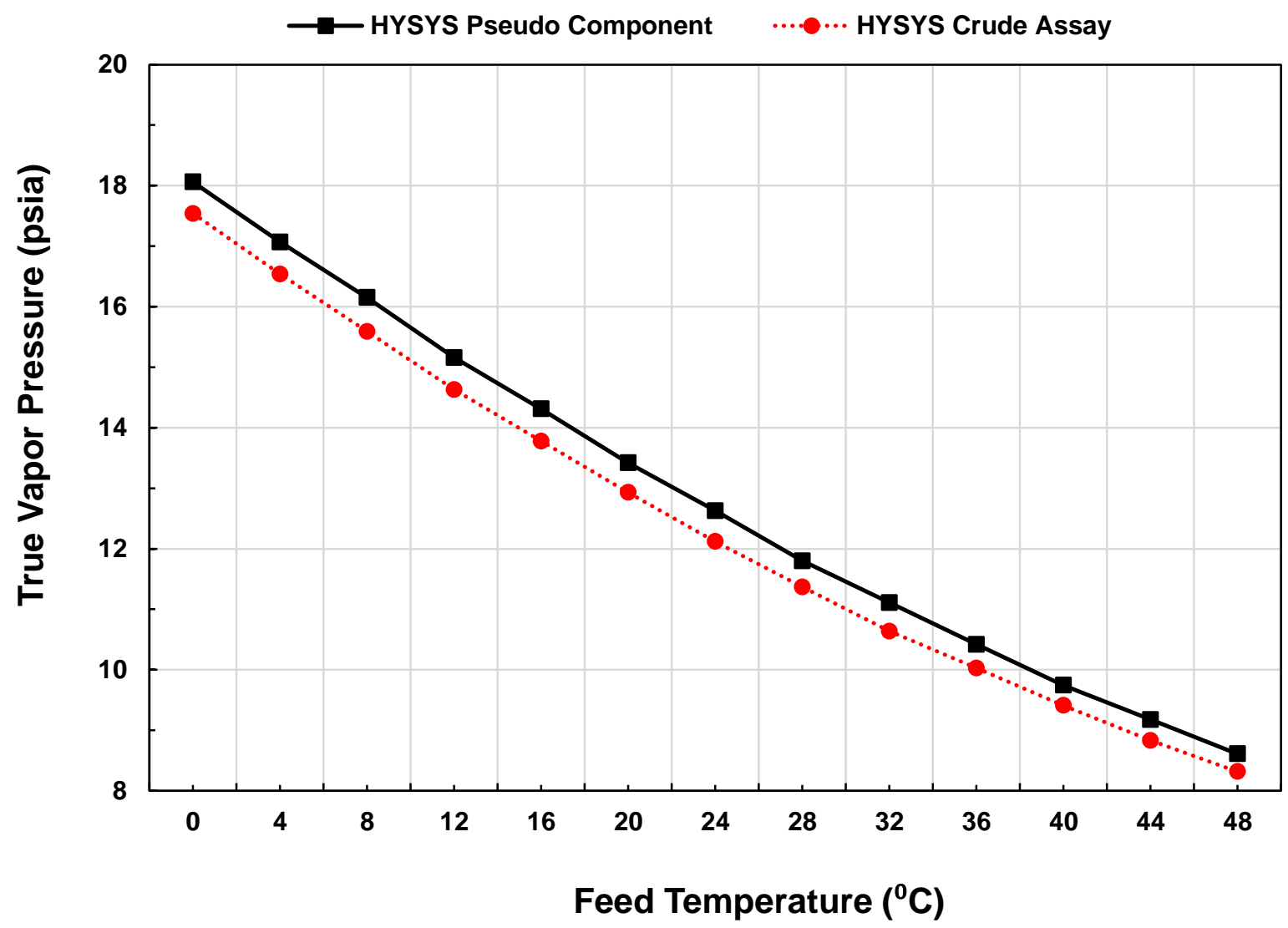

Figure 7: Effect of Feed Temperature on the TVP of the product.

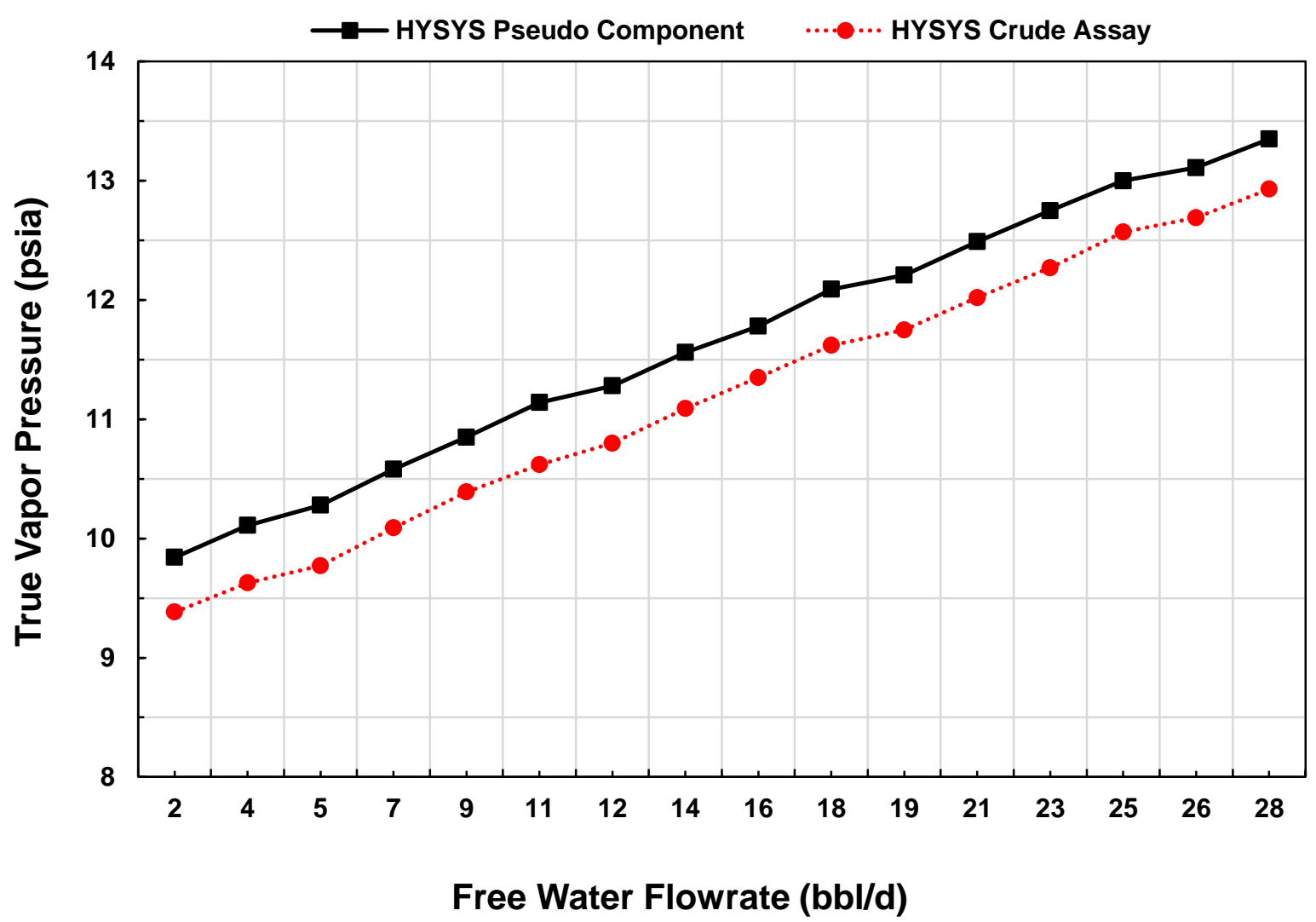

Figure 8: Effect of Water Flow Rate on the TVP of the product. 


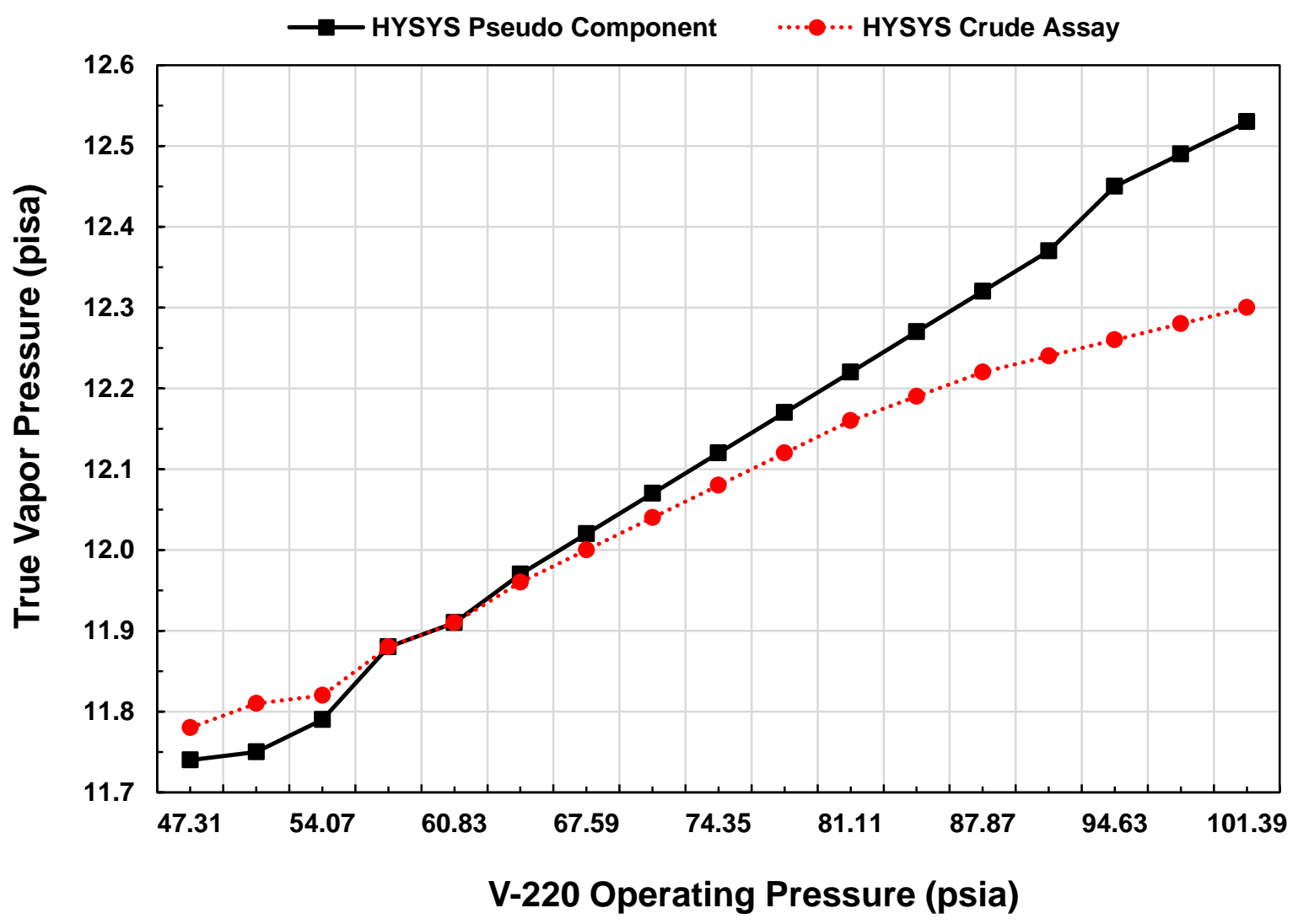

Figure 9: Effect of High Pressure Separator Operating Pressure on the TVP of the product.

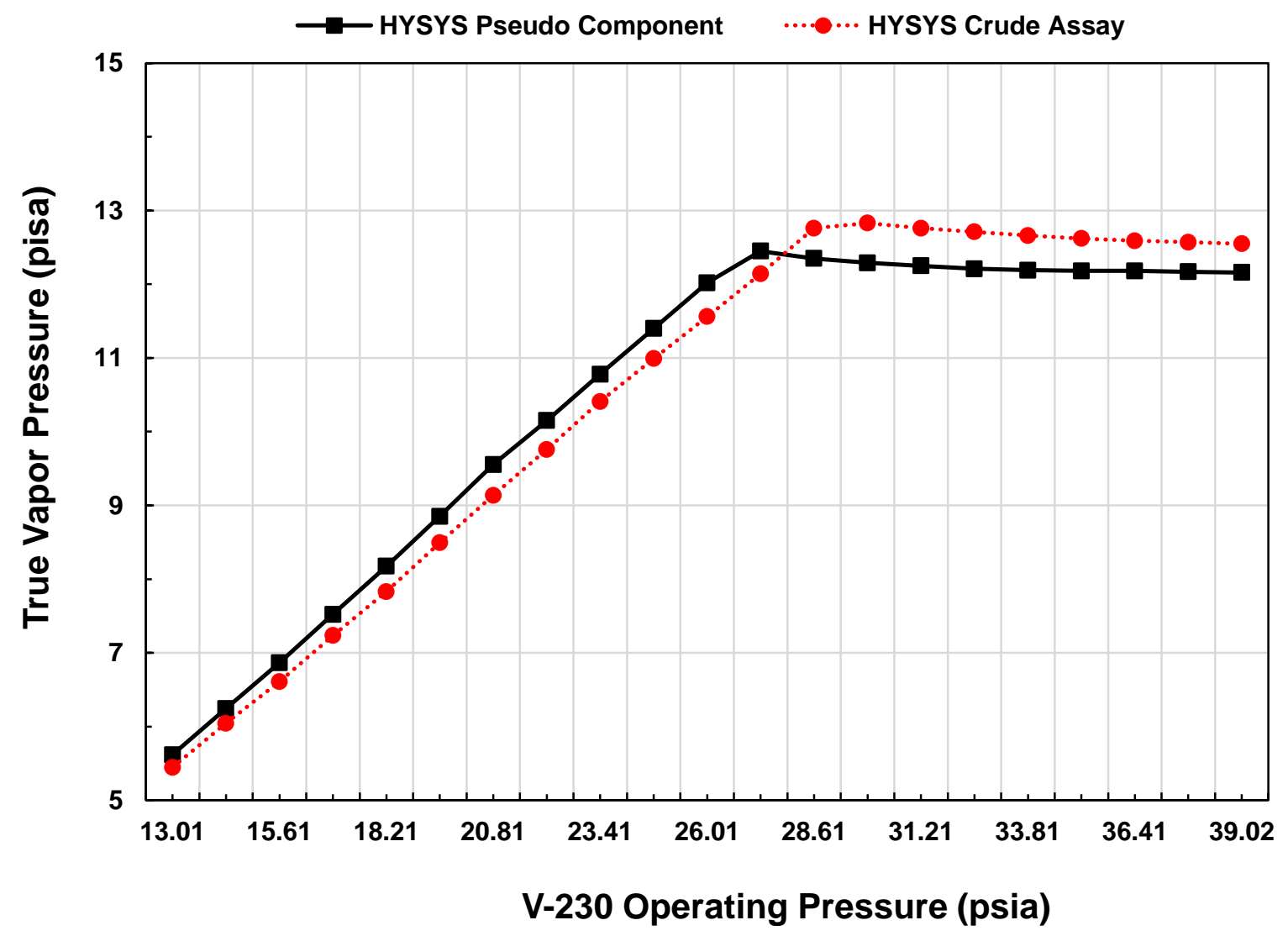

Figure 10: Effect of Low Pressure Separator (V-230 A/B), Operating Pressure on the TVP of 
the product.

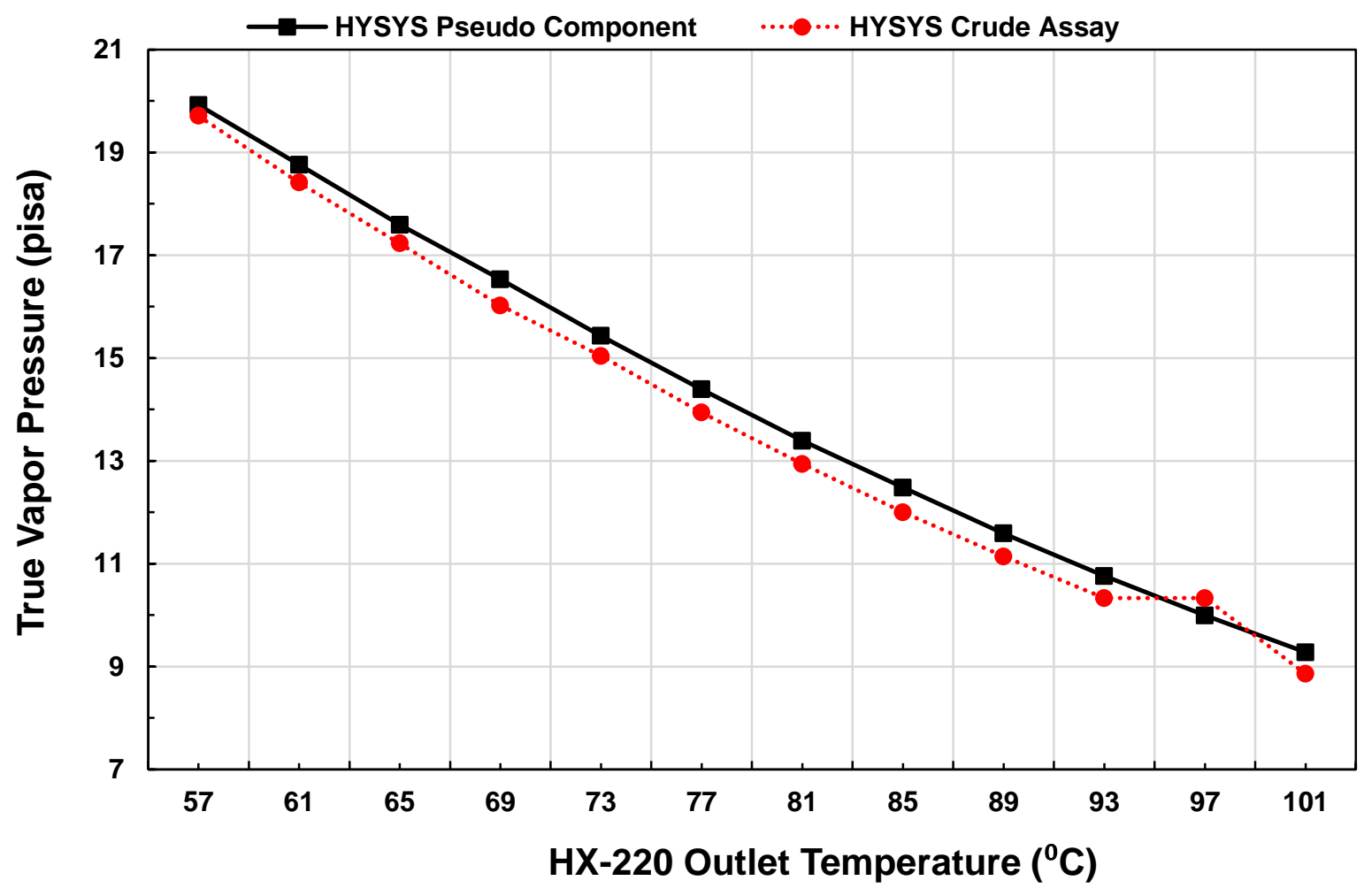

Figure 11: Effect of HX-220s Outlet Temperature on the TVP of the product. 
Table 1 : The desired crude oil specifications.

\begin{tabular}{|c|c|}
\hline Constituent & Limit \\
\hline Methane & $100 \mathrm{ppm}$ \\
Ethane & $0.20 \mathrm{vol} \%$ \\
Propane & $1.00 \mathrm{vol} \%$ \\
Hydrogen Sulphide & $50 \mathrm{ppm}$ \\
Carbon Dioxide & $100 \mathrm{ppm}$ \\
Basic Sediment \& Water (BS\&W) & $0.5 \mathrm{vol} \%$ \\
Maximum True Vapor Pressure & $12 \mathrm{psia}$ \\
\hline
\end{tabular}


Table 2 : Feed stream conditions and composition.

\begin{tabular}{|c|c|c|c|}
\hline Component & Mole Fraction & Component & Mole Fraction \\
\hline Hydrogen & 0 & $\mathrm{C}_{11}$ & 0.047 \\
\hline $\mathrm{H}_{2} \mathrm{~S}$ & 0 & $\mathrm{C}_{12}$ & 0.041 \\
\hline $\mathrm{CO}_{2}$ & 0.005 & $\mathrm{C}_{13}$ & 0.042 \\
\hline Nitrogen & $3 \mathrm{E}-04$ & $\mathrm{C}_{14}$ & 0.038 \\
\hline Methane & 0.041 & $\mathrm{C}_{15}$ & 0.041 \\
\hline Ethane & 0.025 & $\mathrm{C}_{16}$ & 0.029 \\
\hline Propane & 0.04 & $\mathrm{C}_{17}$ & 0.024 \\
\hline i-Butane & 0.025 & $\mathrm{C}_{18}$ & 0.024 \\
\hline n-Butane & 0.029 & $\mathrm{C}_{19}$ & 0.019 \\
\hline Neo-Pentane & $1 \mathrm{E}-04$ & $\mathrm{C}_{20}$ & 0.016 \\
\hline i-Pentane & 0.03 & $\mathrm{C}_{21}$ & 0.014 \\
\hline n-Pentane & 0.021 & $\mathrm{C}_{22}$ & 0.012 \\
\hline Hexane & 0.05 & $\mathrm{C}_{23}$ & 0.01 \\
\hline M-Cyclo Pentane & 0.013 & $\mathrm{C}_{24}$ & 0.009 \\
\hline Benzene & 0.003 & $\mathrm{C}_{25}$ & 0.008 \\
\hline Cyclo-hexane & 0.01 & $\mathrm{C}_{26}$ & 0.007 \\
\hline Heptane & 0.046 & $\mathrm{C}_{27}$ & 0.007 \\
\hline M-C-Hexane & 0.026 & $\mathrm{C}_{28}$ & 0.006 \\
\hline Toluene & 0.012 & $\mathrm{C}_{29}$ & 0.006 \\
\hline Octanes & 0.059 & $\mathrm{C}_{30}$ & 0.005 \\
\hline E-Benzene & 0.003 & $\mathrm{C}_{31}$ & 0.004 \\
\hline M/P-Xylene & 0.018 & $\mathrm{C}_{32}$ & 0.003 \\
\hline O-Xylene & 0.005 & $\mathrm{C}_{33}$ & 0.003 \\
\hline Nonanes & 0.044 & $\mathrm{C}_{34}$ & 0.002 \\
\hline $1,2,4-\mathrm{TMB}$ & 0.007 & $\mathrm{C}_{35}$ & 0.002 \\
\hline Decanes & 0.049 & $\mathrm{C}_{36}$ & 0.018 \\
\hline Total & & & 1 \\
\hline Properties & & & \\
\hline Pressure, bar & & & 17 \\
\hline Temperature, ${ }^{0} \mathrm{C}$ & & & 27 \\
\hline Normal Flow, kbbl/day & & & 195 \\
\hline Entrained Water Content, vol\% & & & 9 \\
\hline Molecular Weight, g/mol & & & 180.6 \\
\hline $\begin{array}{c}\text { Measured Density @ } 15.6{ }^{\circ} \mathrm{C} \text {, } \\
\text { g/cm } 3\end{array}$ & & & 0.82 \\
\hline
\end{tabular}


Table 3: Different Between Design and Current Operation

\begin{tabular}{|c|c|c|}
\hline Parameter & Design Specifications & Current Operation \\
\hline Crude Flow, bbl/d & 442 & 175 \\
Hot Oil Inlet Temperature, ${ }^{\circ} \mathrm{C}$ & 150 & $130-150$ \\
Hot Oil Outlet Temperature, ${ }^{\circ} \mathrm{C}$ & 260 & $190-210$ \\
Stack/Flue Gas Temperature, ${ }^{\circ} \mathrm{C}$ & 197 & $190-200$ \\
No. of Fired Heater In Operation & $2+2(12$ burners $)$ & $3+0(12-13$ burners $)$ \\
\hline
\end{tabular}

*Fired heater HX-610A is under maintenance 